\title{
Quercetin 3-galactoside from Azadirachta indica
}

\author{
Pasupuleti Sreenivasa Rao*1a,b, Gangapatnam Subramanayam², Perali Ramu Sridhar ${ }^{3}$ \\ ${ }^{1 a}$ Research Scientist, Department of Advanced Research Centre, Narayana Medical College \\ ${ }^{1 b}$ Research Advisory Professor, Narayana College of Pharmacy, Nellore, Andhra Pradesh -524002, India \\ ${ }^{2}$ Director/cardiologist,Department of Cardiology / Department of Advanced Research Centre, Narayana Medical \\ College, Nellore, AP-524002, India \\ ${ }^{3}$ Associate Professor, School of Chemistry, University of Hyderabad,Prof. C. R. Rao Road, Gachibowli Hyderabad, \\ 500046 , India \\ Email: sraopasupuleti@yahoo.com
}

\begin{abstract}
Majority of world population up to 80 percent, still relies on traditional medicine. Presently usage of medicinal plant/herbal medicine for treating various disorders and diseases is rapidly growing and they are assumed to have minimal side effects. In ethno traditional medicine Azadirachta indica (Neem) is widely used for centuries. In India, it is extensively used in several native medical practices. Its vegetative parts like leaves, flowers, fruits, seeds and bark are known to possess numerous bioactive compounds, so they are affectionately called as store house of phytochemicals or Village Pharmacy. Its chemical composition is quite complex and few studies effectively characterized and separated few bioactive compounds which has significant biological activities. However, in the current study, we identified, the presence of flavonol galactoside in the neem extracts related to various vegetative parts using LC -MS (Liquid Chromatography and Mass Spectroscopy) spectral analysis. Moreover for the first time, we report the presence of major flavonol galactosides like Quercetin 3-galactoside $\left(\mathrm{C}_{21} \mathrm{H}_{20} \mathrm{O}_{12}\right)$ from the vegetative parts of Azadirachta indica collected from Tirumala Hills, Eastern Ghats.
\end{abstract}

Keywords: Flavonoids, Quercetin 3-galactoside, Azadirachta indica, Natural products, LC -MS

\section{Introduction}

Globally, 80 percent of world population still depends on traditional medicine. Particularly, the usage of medicinal plant/herbal medicine for treating various disorders and diseases is rapidly growing and presumed with minimal side effects [1]. The active compounds existing in these Medicinal /herbal plants have been shown to efficiently slowdown the disease or disorder symptoms in a synergistic manner. This active compound may be of polysaccharides, pigments, steroids, terpenoids, flavonoids and alkaloids etc. Previous studies established that Medicinal/herbal plant extracts and purified compounds have major effect in controlling and eradicating various diseases and disorders [1-8].

Azadirachta indica is an important medicinal plant, belongs to the family Meliaceae, also popular as "village pharmacy" and widely used in various health practices in rural India. It is in cosmopolitan distribution, covering majorly tropics, starting from Asia to Africa [9-12]. It has unique names, commonly referred to as 'Neem tree', or nature's 'drug store' or 'store house of phytochemicals'. They have been explored for centuries, employed in several native ethno-traditional medicinal health practices, and also its vegetative parts like, roots, leaves, bark, seeds and flowers have been used to treat various acute and chronic diseases and disorders [9-12]. Its chemical composition is quite complex and they are potential targets for various phytochemical investigations [10-11]. The vegetative parts are also known to possess diverse range of phytochemicals with potential biological and pharmacological properties. A few studies explained that some of the purified bio-active molecules may possess anti-cancer, antimalarial, anti-bacterial, anti-fungal, anti-viral and anti-inflammatory properties, while a few others have insecticidal; larvicidal and spermicidal properties [9-12].

Studies reveal that nearly 300 plus bioactive compounds have been identified, most of them were chemically diverse, with their complex structures [9,12-13]. Majorly they are differentiated into two categories namely isoprenoids, and non-isoprenoids. The isoprenoids group possess diterpenoids, 
triterpenoids, vilasinins, limonoids, and C-secomeliacins. The nonisoprenoids group is comprised of proteins, polysaccharides, sulphur compounds, polyphenolics, dihydrochalcone, coumarin, tannins and aliphatic compounds $[9,12,14]$. Various studies conclude that most African and Asian Azadirachta indica species have been effectively studied, characterized, and structurally elucidated [9-12]. However, there is no report on the chemical composition of South Indian species especially from the region of Eastern Ghats. Therefore the current study is undertaken to assess the presence of the bioactive molecules like Quercetin 3-galactoside from Azadirachta indica.

\section{Materials and Methods}

\section{a. Plant Collection}

The Azadirachta indica germplam was collected during the month of March, 2017 from the Tirumala hills, Eastern Ghats (Andhra Pradesh) of India. It was authenticated by Local taxonomist. The collected germplasm (leaves, bark and roots) were subjected to shade dry as per described protocols [3-5]. Further germplasm (leaves, bark and roots) were crushed and grinded in a mixer thoroughly to create a fine powder.

\section{b. Preparation of Azadirachta indica Extracts}

The aqueous extracts were prepared from various vegetative parts of Azadirachta indica germplasm comprising of leaves, bark and roots using Soxhlet apparatus. From each various vegetative part, 15 gram of the powder was weighed separately in digital balance and packed into sterile cloth and placed in thimble. Later the double distilled water $(200 \mathrm{ml})$ was filled in the round bottom flask, attached to a Soxhlet extractor, condenser and whole set up placed on a heating mantle. The side arm was insulated with glass wool. The water is heated with the heating mantle, and begins to vaporise through the apparatus and into the condenser, where condensation takes place, and drops into the reservoir holding the thimble. Water after reaching the threshold point in the siphon, goes back into the flask, and the fresh cycle starts. This cycling process was performed for nearly 72 hours. After finishing this process, the obtained water extracts were further subjected to further vaporisation in a distillation unit, to remove the water content and the obtained extracts about 7 to $9 \mathrm{ml}$ placed in the falcon tubes. Later these falcon tubes are subjected to boiling water bath at $60^{\circ} \mathrm{c}$ to remove the moisture content. The final extract was filtered and concentrated, and the residue was dissolved in sterile water and filtered and was kept refrigerated until use. The concentration of the extract was calculated based on the dry weight per unit volume according to the described procedures.

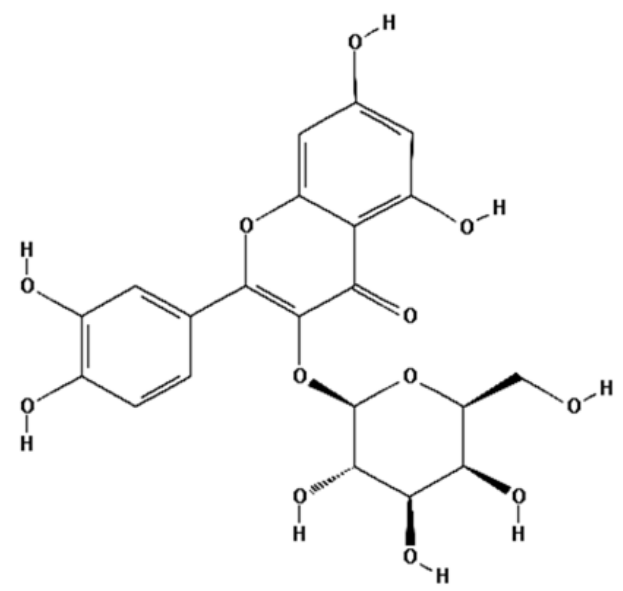

Quercetin 3-galactoside $\mathrm{C}_{21} \mathrm{H}_{20} \mathrm{O}_{12}$ (Mass $464.3 \mathrm{~m} / \mathrm{z}$ )

Figure 1. The structural presentation of identified flavonol galactoside from Azadirachta indica 


\section{c. LC-Mass Spectral Analysis}

The fresh Azadirachta indica germplam aqueous extracts were subjected to chemical fingerprinting using LC-Mass spectral analysis (SHIMADZU-LC-MS-2010A) according to the described procedures [3]. The LC-MS (Liquid Chromatography and Mass Spectroscopy) experiments were carried out using SHIMADZU-LC-MS (Model: 2010A). The mobile phase includes combination of methanol and water, a gradient method was followed, using RP-C18 analytical column $[240 \mathrm{~mm} \times 2 \mathrm{~cm}]$ with a flow rate of 0.5 $\mathrm{ml} / \mathrm{min}$ respectively. The experimental samples were nebulized with nitrogen gas and the ion mass (Electro Spray Ionization) of the peaks generated in both positive mode and negative mode.

\section{Results}

In most plants, flavonoids remains as prominent secondary metabolites, and the structure is recognized with 15-carbon skeleton, attached with two phenyl rings (A \& B) and one heterocyclic ring (C), and commonly abbreviated as $\mathrm{C} 6-\mathrm{C} 3-\mathrm{C} 6$, as per IUPAC nomenclature. In general galactoside is a glycoside containing galactose, in which $\mathrm{H}$ of $\mathrm{OH}$ group on carbon-1 of galactose is exchanged through an organic moiety. Further classification of the galactosides is based on their glycosidic bond linkage either above" or "below" the plane of the galactose molecule. If it lies below the plane called as $\alpha$-galactosides or above the plane termed as $\beta$-galactosides. Further, the glucoside is also termed as a glycoside, which is obtained from glucose. These glucosides are widely observed in most plants. Furthermore, Glucose is derived when glucoside is hydrolysed by means of certain chemical degeneration, or fermentation process or enzyme process. Flavonoids in combination with galactoside result in the formation of flavonol galactosides. These molecules are also referred as organic compounds known as flavonoid-3-o-glycosides. In other words, phenolic compounds contain a flavonoid moiety which is O-glycosidically connected to carbohydrate moiety at the C3-position.

Table 1. Quercetin-3-galactoside presence in various vegetative parts of Azadirachta indica

\begin{tabular}{|c|c|c|c|c|c|c|c|c|}
\hline \multirow{2}{*}{$\begin{array}{l}\text { Name of the } \\
\text { Identified } \\
\text { Molecule in the } \\
\text { LCMS spectra }\end{array}$} & \multirow[t]{2}{*}{$\begin{array}{l}\text { Molecular } \\
\text { formula }\end{array}$} & \multirow[t]{2}{*}{$\begin{array}{l}\text { Mass } \\
(m / z)\end{array}$} & \multicolumn{2}{|c|}{$\begin{array}{l}\text { Presence/Absence of } \\
\text { molecule in the LC MS } \\
\text { spectra of Root extract }\end{array}$} & \multicolumn{2}{|c|}{$\begin{array}{l}\text { Presence/Absence of } \\
\text { molecule in the LC MS } \\
\text { spectra of Bark extract }\end{array}$} & \multicolumn{2}{|c|}{$\begin{array}{l}\text { Presence/Absence of } \\
\text { molecule in the LC MS } \\
\text { spectra of Leaf extract }\end{array}$} \\
\hline & & & $\begin{array}{l}\text { positive } \\
\text { mode }\end{array}$ & $\begin{array}{l}\text { negative } \\
\text { mode }\end{array}$ & $\begin{array}{l}\text { positive } \\
\text { mode }\end{array}$ & $\begin{array}{l}\text { negative } \\
\text { mode }\end{array}$ & $\begin{array}{l}\text { positive } \\
\text { mode }\end{array}$ & $\begin{array}{l}\text { negative } \\
\text { mode }\end{array}$ \\
\hline $\begin{array}{l}\text { Quercetin-3- } \\
\text { galactoside }\end{array}$ & $\mathrm{C}_{21} \mathrm{H}_{20} \mathrm{O}_{11}$ & 464.3 & yes & no & yes & yes & yes & yes \\
\hline
\end{tabular}

In the present investigation we studied the distribution pattern of flavonol galactosides like Quercetin 3-galactoside in the vegetative parts of Azadirachta indica which was collected from Eastern Ghats (Andhra Pradesh, India). After collection, the Plant germplasm was shade dried, subjected to grinding and made into fine powder. Next, this powdered material from various vegetative parts was subjected to extraction with water as a solvent using soxhlet apparatus. The water extracts were collected, further sterile filtrated individually and subjected to spectral analysis. Further an analytical method like LC-MS (ESI) was employed to acquire chemical fingerprint profile of the aqueous extracts of Azadirachta indica. The LC-MS spectral data demonstrated the presence of Quercetin 3-galactoside in the extracts, with their protonated molecular ions, respective $\mathrm{m} / \mathrm{z}$ observed in both positive mode (Fig.2A-4A) and as well as in the negative mode (Fig. 2B-4B, Table-1).

\section{Root Extract}

The LC-MS spectral data of Azadirachta indica root extract displays the presence of a molecular ion peak of Quercetin 3-galactoside $\left(\mathrm{C}_{21} \mathrm{H}_{20} \mathrm{O}_{12}\right)$ at $464.3 \mathrm{~m} / \mathrm{z}$ respectively. The protonated molecular ion peaks of this molecule were recorded in positive mode (Fig. 2A) and completely absent in negative mode (Fig. 2B). 


\section{Bark Extract}

Similar findings were noticed in the bark extract. The LC-MS spectral profile of aqueous bark extract of Azadirachta indica reported the presence of a molecular ion peak of Quercetin 3-galactoside $\left(\mathrm{C}_{21} \mathrm{H}_{20} \mathrm{O}_{12}\right)$ at $464.3 \mathrm{~m} / \mathrm{z}$ respectively. The protonated molecular ion peaks of Quercetin 3-galactoside were clearly observed in positive mode (Fig. 3A) and as well as negative mode (Fig. 3B).

\section{Leaf Extract}

The aqueous leaf extract of Azadirachta indica was also presented with similar findings. The LC-MS spectral data of aqueous leaf extract reveals the presence of a molecular ion peak of Quercetin 3galactoside $\left(\mathrm{C}_{21} \mathrm{H}_{20} \mathrm{O}_{12}\right)$ at $464.3 \mathrm{~m} / \mathrm{z}$ respectively. The protonated molecular ion peaks of Quercetin 3galactoside were clearly reported in positive mode (Fig. 4A) and as well as negative mode (Fig. 4B).

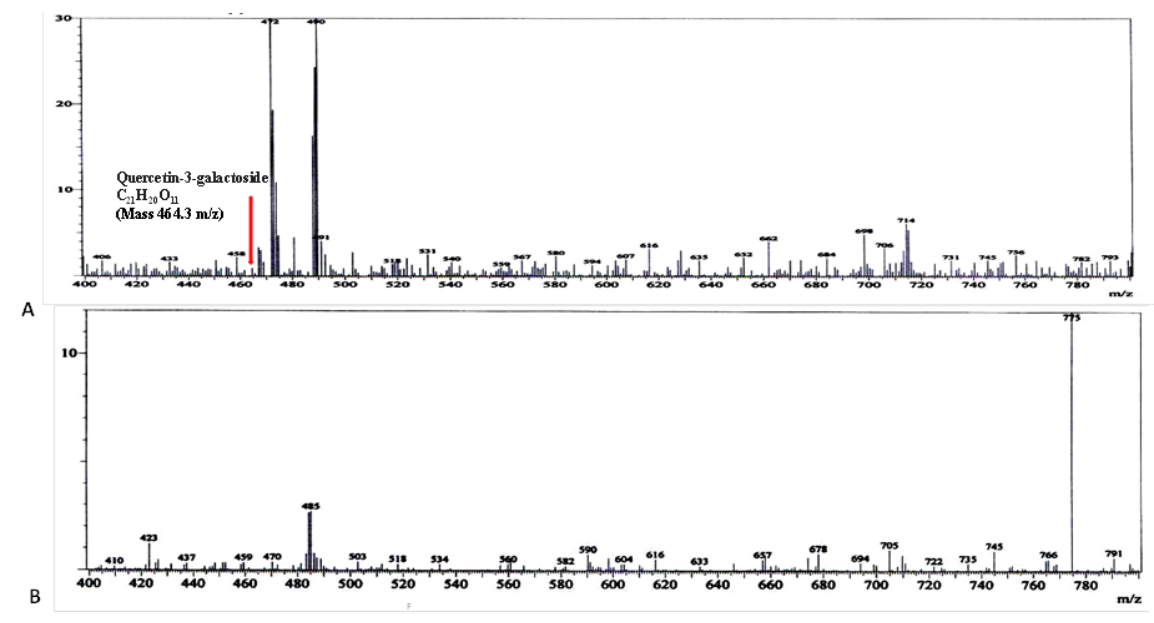

Figure 2. A (Positive mode)-B (Negative mode). The LC-MS spectral analysis (Positive mode and negative mode) of crude aqueous root extract of Azadirachta indica displays the presence of a molecular ion peak of Quercetin 3galactoside $\left(\mathrm{C}_{21} \mathrm{H}_{20} \mathrm{O}_{12}\right)$ at $465.3 \mathrm{~m} / \mathrm{z}$ respectively

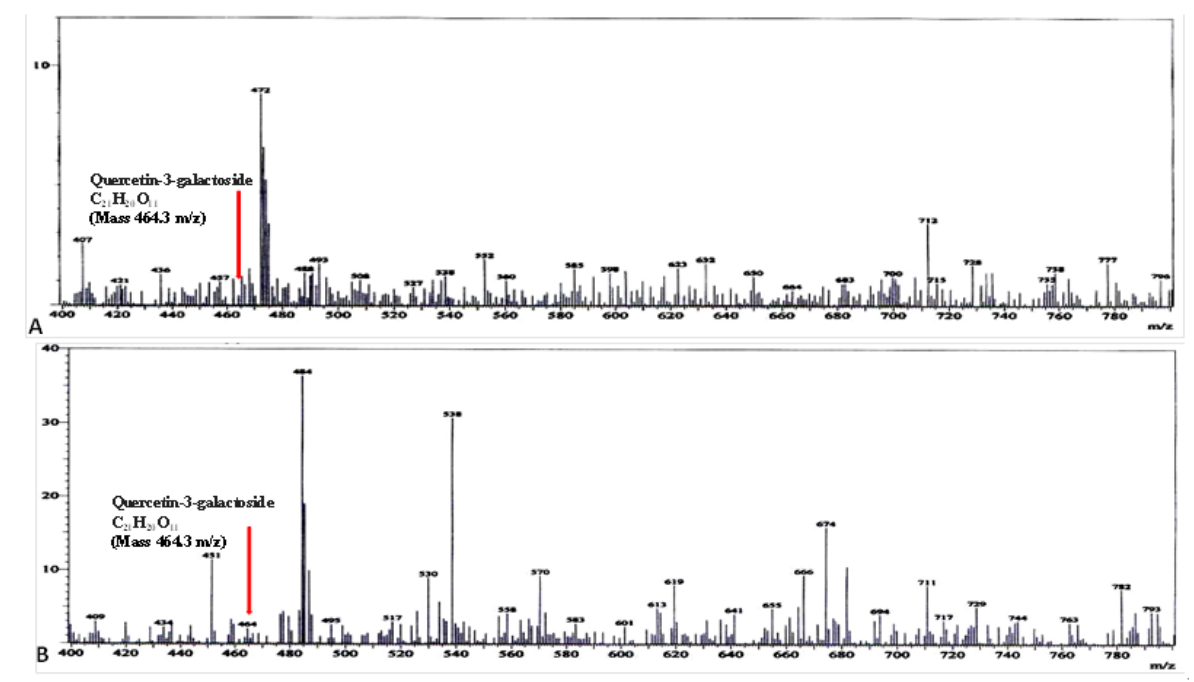

Figure 3. A (Positive mode)-B (Negative mode). The LC-MS spectral analysis (Positive mode and negative mode) of crude aqueous bark extract of Azadirachta indica displays the presence of a molecular ion peak of Quercetin 3galactoside $\left(\mathrm{C}_{21} \mathrm{H}_{20} \mathrm{O}_{12}\right)$ at $465.3 \mathrm{~m} / \mathrm{z}$ respectively 


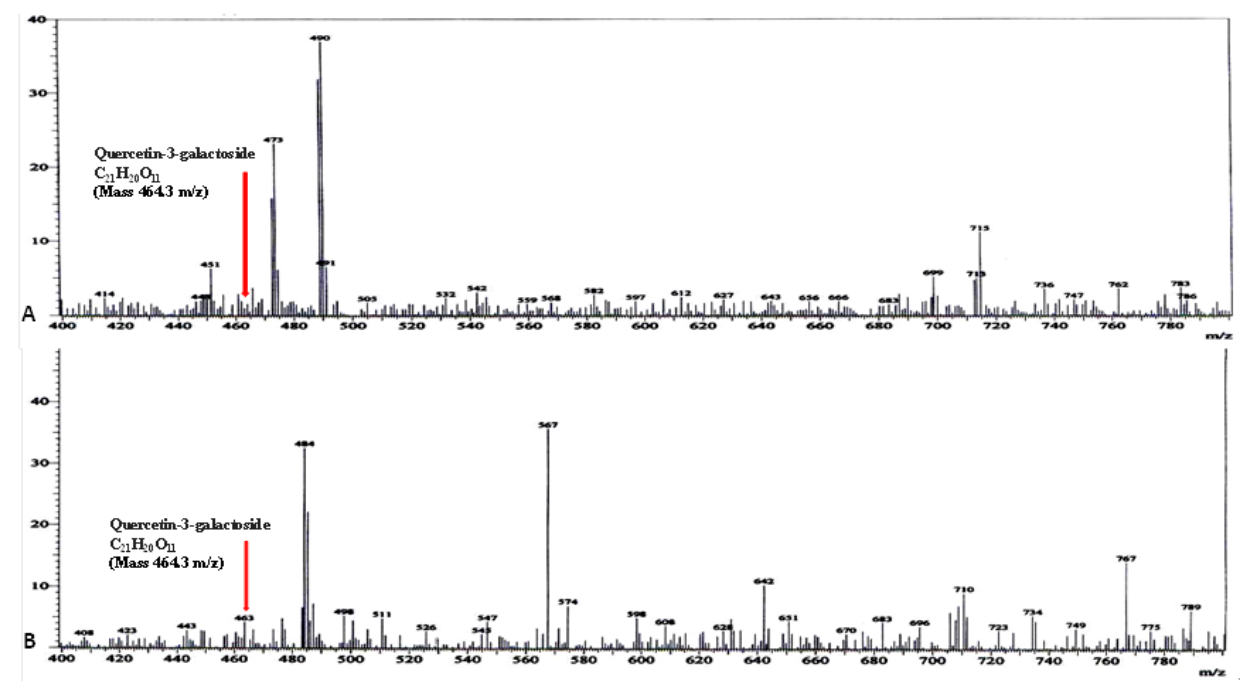

Figure 4. A (Positive mode)-B (Negative mode). The LC-MS spectral analysis (Positive mode and negative mode) of crude aqueous leaf extract of Azadirachta indica displays the presence of a molecular ion peak of Quercetin 3galactoside $\left(\mathrm{C}_{21} \mathrm{H}_{20} \mathrm{O}_{12}\right)$ at $465.3 \mathrm{~m} / \mathrm{z}$ respectively

\section{Discussion}

The chromatographic techniques are extensively used in studying the natural products or synthetic molecules, which will fight against various diseases and disorders. Recent advances in modern molecular biological tools like DNA sequencing, genetic engineering, gene targeting and transgenic methodologies have showed a new path to better understand and analyze the infections, diseases and disorders, which provides novel options for developing new age therapeutics [15-18]. Presently, to fight with diseases like cancer [15-19] and disorders like diabetes [20], numerous efficient drug development technologies have been established through programs like in silico drug designing as well as synthesis of various novel molecules [5, 21-24], however the problems continue the same. Therefore alternatives are required.

Medicinal plants appear as better option. In ethno-traditional medicine, medicinal plants have been effectively used to treat a variety of diseases and disorders [6-8]. Presently, administration of the medicinal plant/herbal extracts/formulations is quickly progressing, and also supposed to have very less side effects. The active compounds present in this may be responsible for this effect. The active compounds may be polysaccharides, pigments, steroids, terpenoids, flavonoids and alkaloids [1, 5-6]. Moreover, in the present scenario identifying these secondary metabolites has become an active field of study, since they are potential sources for unique drugs $[1,3]$. Most studies principally reveal that these plant secondary metabolites will be separated by various chromatographic methods like extraction, separation, purification, structural elucidation and quantification [1-5]. Initially various vegetative parts of the plant germplasm were collected, shade dried, lyophilized, further extracted with appropriate solvents using soxhlet extractor. After extraction, desirable bioactive compounds will be separated, purified, structure elucidated and quantified by using suitable chromatographic methods. However, the above said applied procedures are time consuming. Recent studies also describe that it is an urgency to adopt and implement new age analytical tools for investigating bioactive compounds. Moreover implementation of new chemical fingerprinting tools like LC-MS, can produce quality results in short span. Hence for better output, these chromatographic fingerprinting methods could be employed in identifying and validating various molecules that completely represent a particular plant or herb.

As stated above, A. indica is widely used in Indian native ethno-traditional medicine and also in various health practices and several studies also demonstrated its significance for treating various diseases and disorders [9-12]. Its active principles were well studied and characterized [11]. Patela et al. (2016) categorized neem active principles into two categories, namely Isoprenoids and non-isoprenoids. In the isoprenoids group the diterpenoids, triterpenoids and steroids were placed. The Falavanoids, coumarins, carbohydrates, proteins, hydrocarbons, fatty acids and esters, and other acids were placed in 
the group of non-isoprenoids. Further, the triterpenoids are subdivided into many types based on the elimination of carbon atom either from the side chain or from the ring skeletal structure of the parent compound. The triterpenoids are further differentiated into protolimonoids, mononortriterpenoids, dinortriterpenoids, trinortriterpenoids, tetranortriterpenoids, pentanortriterpenoids, hexanortriterpenoids, octanortriterpenoids and nonanortriterpenoids. Furthermore tetranortriterpenoids were separated into two groups, namely ring-intact- tetranortriterpenoids and ring-seco-tetranortriterpenoids. The diterpenoids were further differentiated into two groups, such as podacarpanoids (margolone) and abeitanoids (sugiol). However, the active chemical composition in plants varies due to their geographical distribution, seasonal variations and other unknown environmental factors [3]. In spite of its therapeutic potential, the chemical composition of A.indica species, distributed in Eastern Ghats (India) has not been studied in detail. Therefore, the present investigation is carried out in aim to report the presence of flavonol galactosides like the Quercetin 3-galactoside $\left(\mathrm{C}_{21} \mathrm{H}_{20} \mathrm{O}_{12}\right)$ in Azadirachta indica.

In the current study, Azadirachta indica germplasm comprising of leaves, bark and roots have been collected, shade dried, lyophilized into fine powder. Next, these powders were extracted with water in soxhlet apparatus and extracts were obtained, further sterile filtrated and sent to LC-MS spectral analysis. The respective molecular mass of the Quercetin 3-galactoside $\left(\mathrm{C}_{21} \mathrm{H}_{20} \mathrm{O}_{12}\right)$ have been observed in all the extracts assessed and (Fig. 2-4, Table 1) presented with their positive and negative ion electrospray mass spectra (ESI-MS), and well as with their corresponding protonated and deprotonated pseudo-molecular ion peaks.

A few plants produce flavonoids, in large number and A.indica is one among them. Flavonoids are unique bioactive compounds, with wide range of biological and physiological activities [25-26]. Flavonoids are called as di-phenyl propanes or C6-C3-C6 ring structures, connected with variety of hydroxyl groups. Majorly they appear in either conjugated forms or their hydroxyl groups linked with one or more sugar residues. Frequently they will be connected with carboxylic acids, amines, lipids and also linked with phenols. A few studies explain that flavonoids exhibit antioxidant activity, based on their connected structure, and also act as reducing agents, hydrogen-donating antioxidants and quenchers of singlet oxygen [26-28]. Thus, in the present study various vegetative parts of A. indica were evaluated to identify the presence of flavonol galactosides like Quercetin 3-galactoside $\left(\mathrm{C}_{21} \mathrm{H}_{20} \mathrm{O}_{12}\right)$, using tools like LC-MS.

The structural presentation of Quercetin 3-galactoside $\left(\mathrm{C}_{21} \mathrm{H}_{20} \mathrm{O}_{12}\right)$ has been reported in Figure 1A. The LC-MS spectral profile of various vegetative parts of crude Aqueous extracts of Azadirachta indica clearly demonstrated the presence of flavonol galactosides like Quercetin 3-galactoside $\left(\mathrm{C}_{21} \mathrm{H}_{20} \mathrm{O}_{12}\right)$, in both positive mode (Fig. 2-4) and negative mode (Fig. 2-4). Quercetin 3-galactoside $\left(\mathrm{C}_{21} \mathrm{H}_{20} \mathrm{O}_{12}\right)$ was identified in all the extracts assessed (Table 1). The results revealed the presence of Quercetin 3galactoside $\left(\mathrm{C}_{21} \mathrm{H}_{20} \mathrm{O}_{12}\right)$ in the spectral data and the molecular ion peaks was observed at $\left(\mathrm{C}_{21} \mathrm{H}_{20} \mathrm{O}_{12}\right)$ at $464.3 \mathrm{~m} / \mathrm{z}$ respectively for all the extracts assessed. Quercetin 3-galactoside $\left(\mathrm{C}_{21} \mathrm{H}_{20} \mathrm{O}_{12}\right)$ was noticed in either positive mode or negative mode or completely absent in few aqueous extracts. The spectral assessment of root extract of Azadirachta indica showed the protonated molecular ion peaks of Quercetin 3-galactoside $\left(\mathrm{C}_{21} \mathrm{H}_{20} \mathrm{O}_{12}\right)$ in positive mode (Fig. 2A) and completely absent in negative mode (Fig. 2B). The spectral data of bark extracts revealed the presence of protonated molecular ion peaks of Quercetin 3-galactoside $\left(\mathrm{C}_{21} \mathrm{H}_{20} \mathrm{O}_{12}\right)$ in positive mode (Fig. 3A) as well as in negative mode (Fig. 3B). Similar findings were observed in case of leaf extract, the protonated molecular ion peaks of Quercetin 3galactoside $\left(\mathrm{C}_{21} \mathrm{H}_{20} \mathrm{O}_{12}\right)$ were noticed in positive mode (Fig. 3A) as well as in negative mode (Fig. 3B). The flavonol glucosides like Quercetin 3-galactoside $\left(\mathrm{C}_{21} \mathrm{H}_{20} \mathrm{O}_{12}\right)$ identified in the present study were correlated with other studies that demonstrated the presence of these molecules [29-30].

\section{Conclusions}

From the above study we conclude that presence of flavonlol galactoside like Quercetin 3-galactoside $\left(\mathrm{C}_{21} \mathrm{H}_{20} \mathrm{O}_{12}\right)$ has been reported for the first time from various vegetative parts of Azadirachta indica collected from Tirumala hills, Eastren Ghats, India.

Conflict of interest. The authors declare that they have no conflict of interest. 


\section{References}

1. Rao PS, Subrahmanyam G (2017) Induction of diabetes by alloxan in male wistar albino rats -a simplified methodology. Euro J Biomed Pharmace sci 6: 13, 68-75

2. Rao PS, Subrahmanyam G, Bhaskar M (2017). U-HPLC (Ultra-High-pressure Liquid Chromatography) Separation of Indole Alkaloid Strychnine. World J of Pharmace Res 4: 11,1022-35.

3. Rao PS, Prasad MNV (2008) Extraction, Purification and Characterization of Indole Alkaloids from Strychnos wallichiana L. - an Endangered Medicinal Plant from India. Medici Aroma Plant Sci Biotech 2: 63-67

4. Rao PS, Ramanadham M, Prasad MNV (2009). Anti-proliferative and cytotoxic effects of Strychnos nux-vomica root extract on human multiple myeloma cell line - RPMI 8226. Food Chem Toxic 47: 283-288.

5. Rao PS, Prasad MNV (2013) The Strychnos nux-vomica root extract induces apoptosis in the human multiple myeloma cell line-U266B1. Cell Biochem Biophy 66:443-450

6. Satyanand V, Reddy CB, RamaMohan P, Kumar MR, Narayanaswamy DL, Seelam A, Ramalingam K, Rao PS (2013a). Effects of Garlic extract (Allium sativum) in combination with Amlodipine in mild to moderate essential hypertensive patients: An Open randomized parallel group study. J Pharmace Res Dev 2(4):181-188.

7. Satyanand V, Venkata Krishnan, Ramalingam K, Rao PS , Priyadarshini S (2013b) Blockade of voltage dependent calcium channels lowers the high blood pressure through ginger Int J Analy, Pharmace Biomed Sci, 2(1): 64-66.

8. Satyanand V, Venkat Krishnan, Madhavi D, Revathi, Indira S, Shaik AB, Rao PS (2013c). The effect of peppermint juice for indigestion among old age people- A preliminary study. J Pharmace Res Dev 2(7): 238-243

9. Akhila, A., Rani, K., (1999) Chemistry of the neem tree (Azadirachta indica A. Juss.).Fortschritte der Chemie organischer Naturstoffe=Progress in the chemistry of organic natural products. Progres dans la chimie des substances organiques naturelles 78: 47-149.

10. Patela SM., Venkata KCN, Bhattacharyya P, Sethi G, Bishayee A (2016). Potential of neem (Azadirachta indica L) for prevention and treatment of oncologic diseases Seminars in Cancer Biology 40-41: 100-115

11. Gupta SC, Prasad S, Tyagi AK, Ajaikumar B. Kunnumakkara, Aggarwal BB (2017). Neem (Azadirachta indica): An indian traditional panacea with modern molecular basis. Phytomedicine 34: 14-20

12. Biswas, K., Chattopadhyay, I., Banerjee, R.K., Bandyopadhyay, U (2002) Biological activities and medicinal properties of neem (Azadirachta indica). Curr. Sci. 82, 1336-1345.

13. Subapriya, R., Nagini, S (2005). Medicinal properties of neem leaves: a review. Curr. Med. Chem. Anti-Canc. Agents 5: 149-146

14. Brahmachari, G (2004) Neem-an omnipotent plant: a retrospection. Chembiochem: 5, 408-421.

15. Suresh G, Gopi Krishna S, Nayudu N, Sravanthi M, Rao PS, Kumar VKM, Sowdamani G, Rudramadevi K, Nagesh N, Manjula B, Kondaiah K, Varadacharyulu N (2014) Contribution of cyclin D1 (CCND1) and Ecadherin (CDH1) alterations to colorectal cancer susceptibility: a case-control study. Tumor Bio doi 10.1007/s13277-014-2505-9

16. Suresh G, Sravanthi M, Bulle S, Dasi D, Prathap BN, Bramhachari PV, Nagesh N, Shivaji S, Bhanoori M, Rao RT, Rao PS, Varadacharyulu N (2016a) Manganese-superoxide dismutase (Mn-SOD) overexpression is a common event in colorectal cancers with mitochondrial microsatellite instability. Tumor Biol 2-4: doi 10.1007/s13277-0164918-0.

17.Suresh G, Bulle S, Sravanthi M, Krishna MT, Nagesh N, Manjula B,Varadacharyulu N, Rao PS (2016) Association of Mitochondrial Displacement Loop Polymorphisms with Risk of Colorectal Cancer in South Indian Population. Mitochondrial DNA .doi.org/10.3109 /24701394.2016b.1160076.

18.Singh S, Kotakonda A, Kapardar R, Kankipati H, Rao PS, Mambatta PS, Vetaikorumagan SR, Gundlapally S, Nagappa R, Shivaji S (2015). Response of bacterioplankton to iron fertilization of the Southern Ocean, Antarctica. Front. Microbiol 6: 863. doi:10.3389/ fmicb.2015.00863

19.Chetan R, Veeresalingam B, Kumar KM, V, Teja PD, Rao PS (2013) A study on the clinical manifestations and the incidence of benign and malignant tumors in a solitary thyroid nodule. Int J Res Medi Sci Nov; 1(4):429-434

20.Reddy S A, Dasu K, Venkat Krishnan, Reddy MR, Jithendra K, Rao PS (2013). Prevalence of asymptomatic bacteriuria and its antibiotic sensitivity in type-2 diabetic women along the sea coast. Int J Res Medi Sci $1(4): 487-495$ 
21.Rao PS, Muvva C, Geethanjali K, Babu BS, Kalashikam R (2012) Molecular docking and virtual screening for novel protein tyrosine phosphatase 1B (PTP1B) inhibitors. Bioinformation 8(17): 834-837.

22. Bola BR, Rao PS, Satish S (2017) Ligand Docking Based Identification of Novel Drug Analog for an Effective Treatment against Filaria, Haya: Saudi J. Life Sci. 2, -9: 335-348.

23.Avinash A, Swarupa SS, Siva K, Sirisha D, Riyaz S, kumar ND, Sreenivasulu M, Rao PS (2015). Design and Evaluation of Famotidine Floating Tablets. Int J Innov Pharmace Res 6 (1):440-445

24. Hymavathi, R, Suresh, G, Sumanth, K.M, Swapna, V.K, Sravanthi, M, Rao, P.S, Manjula, B, Varadacharyulu, N (2017). Therapeutic effect of green tea extract on alcohol induced hepatic mitochondrial DNA damage in albino wistar rats. J Adv Res 8(3): 289-295.

25. Cuyckens F, Claeys M. (2004). Mass spectrometry in the structural analysis of flavonoids. J Mass Spectrom. 39:1-15.

26. Cook NC, Samman S (1996). Flavonoids - chemistry, metabolism, cardioprotective effects, and dietary sources. J Nutr Biochem 7:66-76.

27. Moure A, Cruz JM, Franco D, Dominguez JM, Sineiro J, Domınguez H, Nu nez MJ, Parajo JC (2001). Natural antioxidants from residual sources. Food Chem. 72:145-171.

28. Bravo L. 1998. Polyphenols: Chemistry, dietary sources, metabolism, and nutritional significance. Nutr Rev $56: 317-333$

29. Keskes H, Belhadj S, Jlail L, Feki A E, Damak M, Sayadi S, Allouche N (2017). LC-MS-MS and GC-MS analyses of biologically active extracts and fractions from Tunisian Juniperus phoenice leaves, Pharmaceutical Biology, 55:1, 88-95

30. Francescato LN, Debenedetti SL, Schwanz TG, Bassani VL, Henriques AT(2013). Identification of phenolic compounds in Equisetum giganteum by LC-ESI-MS/MS and a new approach tototal flavonoid quantification Talanta 105:192-203. 